\title{
THE BEST PRACTICES OF ONLINE PRESIDENTIAL COMMUNICATION IN DEMOCRATIC STATES ROMANIA, REPUBLIC OF MOLDOVA AND RUSSIAN FEDERATION
}

\author{
Liliana Rusu ${ }^{1}$
}

\begin{abstract}
The Presidential Communication is defined as the dissemination, by the president or the presidential institution, of the public or national interest information. The interactive model, with its connotation of public deliberation renovated form, is the most egalitarian and democratic model of presidential political communication.
\end{abstract}

Currently, in most European democratic states, the "true public deliberation" is favored by political websites which allow the two-way communication and the three-way communication. Among the most interactive elements of the websites the researchers have identified the following: active email to political leader or contact forms, e-subscriptions, forums, site search engine.

Presidency website is the main form of new media involved in the presidential political communication of the Republic of Moldova. Mapping the website, content analysis, interpretation of results - are the methods which have been used for the purposes to assess the effectiveness of communication between Head of State and citizens from the online environment. Contrastive analysis of new media, applied for the presidential communication by Nicolae Timofti, Klaus Iohannis, Vladimir Putin, has served to determine the best practices and to develop recommendations for optimizing online presidential communication of the Republic of Moldova.

Key words: presidential communication, new media, interactivity, public deliberation, democracy.

\section{Introduction. Theoretical and Methodological aspects}

Presidency website is the main form of new media involved in the presidential political communication of the Republic of Moldova. Mapping the website, content analysis, interpretation of results - are the methods which have been used for the purposes to assess the effectiveness of communication between Head of State and citizens from the online environment. Contrastive analysis of new media, applied for the presidential communication by Nicolae Timofti, Klaus Iohannis, Vladimir Putin, has served to determine the best practices and to develop recommendations for optimizing online presidential communication of the Republic of Moldova.

\section{Contrastive and content analysis of new media}

The official website of the Ex-President Nicolae Timofti was created in 2013 and summarizes the Moldovan Presidency's efforts concerning the promotion and visualization of political activity of the president. Overall, we note that this online communication platform tends towards the respect of

\footnotetext{
${ }^{1}$ PhD Student, Moldova State University, rusuliliana9@gmail.com
} 
international standards regarding the creation of institutional websites, including in the category of technical aspects the following elements: sitemap, site search engine, information in various formats (text, images, audio, video), the print button for articles, external links. The chromatic of this website home page, expressed by the alternation of the two dominant colors - blue and white, corresponds to the action to popularize the message of the President and to strengthen the image of the country's most important political actor. The experts in the field have found that cool shades, especially blue and green colors, are associated by receivers of political information with the condition of state security, pragmatism and professionalism. The white color is considered by semioticians as active one, which gives brightness, clarity, and the feeling of closeness to the object. Thus, the chromatic message of presidential official website complies is within the limits of traditional discourse, ritualized and sober, being fully consistent with the tasks of the Head of State as the guarantor of "national sovereignty, independence, unity and territorial integrity" [7]. In the upper part of the main page of this official website is another important visual element - the State Emblem of the Republic of Moldova, which enhances the communication semantics, giving it a surplus of sobriety and credibility by the presence of this major symbol of independence and indivisibility of the Republic of Moldova. In the lower part of this page, the line decorated in traditional style suggests the idea of stability and respect for the tradition and the country's historical past, and as while the image of national flag inserted into a circle - express the message of the fourth President of the Republic of Moldova (elected by Parliament on 16 March 2012) to promote the state policy of adherence to the EU.

The official website of Mr. Klaus Iohannis, the President of Romania, complies with the same strictness on chromatic aspect: deep blue color outlines the upper part of the site, with links to the main information and the lower part of the first page of that online communication platform. The white color occupies more space - the middle part of this website. Nevertheless, the titles and characters too small, in blue color, diminish the ability for and reading and receiving the political message. So, the overall image of this site, resulting in alternating of white and blue expresses a speech perceived on the basis of main visual elements as cold, too rigorous and distanced from the public.

On the official website of Mr. Vladimir Putin, the President of Russian Federation, prevail the both shades of blue - dark and light blue, which marks the contrast between the upper, the lower and the left parts of the website, where is the list of main information, and the middle part of this online communication platform, where this information can be accessed, viewed and received by the Internet users. Unlike the official website of Mr. Nicolae Timofti, the Ex-President of the Republic Moldova, the online communication platform of the President of Russian Federation includes only the State Emblem of as a visual element, the nation flag being present only in the section State insignia and on some photos were can be seen the most important moments of the activity of the Chief of the State.

By studying the rich history of the blue color and its semantics in the context of social codes of the modern state, Michel Pastoureau concluded that it is the favorite color of most Western European states [5]. Important international organizations as United Nations, the Council of Europe, the European Union chose this emblematic color for the connotation of major political values: peace, solidarity, freedom of speech. In the case of the official website of Mr. Nicolae Timofte, the ExPresident of the Republic of Moldova, the use of the light blue in the process of political communication is the expression of the message focused on maintaining stability and unity of the State. The Deep blue color from the official website of Mr. Klaus Iohannis, the President of Romania, expresses his calm nature and his tendency for action with slow but certain steps towards 
the development of a prosperous democratic European state. The contrast between light and dark blue from the official website of Mr. Vladimir Putin, the President of Russia, expresses the message of a powerful political leader, authoritarian personality and the main guarantor of the respect of the Constitution, of rights and freedoms of citizens of the state that he represents.

Prof. Calin Sinescu, Romanian specialist in political science, said that one of the first uses of the Internet was as "an important source of political information" and "strategic tool", which according to survey results has demonstrated, during the election period, the ability to increase the number of voters, helping them by providing the necessary information "to decide for whom to vote" [6, $\mathrm{p}$. 250]. In the case of political websites, he delimits all the information posted on these online communication platforms into three basic categories: 1. data for external public, 2.information for journalists, 3 . information for the militants.

The Presidential Communication, as institutional political communication, can be included in the category of a permanent electoral communication, ensured by the continuous flow of information regarding the activity of the Chief of the State and concerning the Presidency. The official websites of Presidents took over this basic function of new media, focusing, first of all, on informing citizens, contributing to the formation and consolidation of civil society political culture. The structural investigation of official website of Mr. Nicolae Timofti, the President of the Ex-President of the Republic of Moldova, has allowed us to identify the presence of the following categories of information in the list from the left part of the home page:

1. President (with the following compartments: Biography, Status and Powers, Oath President, History);

2. Press Service (where are presented: Press Releases, Speeches and Messages, Interviews, Photo Gallery, Video Gallery);

3. Supreme Security Council (where can be accessed and can be reading Releases, information on the structure of the Supreme Security Council and legal framework);

4. Administration of the President (with the list of officials - staff members of this structure);

5. First Lady (where are posted the following information: Biography, Social involvement, Events, Interviews, Photo Gallery, Video Gallery);

6. Republic of Moldova (where are posted, can be accessed, printed and read the two very important documents for the development of state of law Republic of Moldova: Declaration of Independence of the Republic of Moldova and Constitution of the Republic of Moldova, data on state symbols, list of links to official websites of relevant organizations (Parliament of the RM, Government of RM, Constitutional Court of RM, Supreme Court of RM, National Bank of Moldova, Academy of Sciences of Moldova, Chamber of Commerce and Industry of the Republic of Moldova etc.), the link to initial version of the official website of the President of $\mathrm{RM})$;

7. Transparency in decision making process (which includes: Decision elaboration, Draft Decisions, Adopted Decisions, Annual Reports - categories that can be accessed, but not containing any information, we can read only the name of a content, which we hope to be posted in the future to inform citizens). 
In the bottom left part, on the home page of the site www.presedinte.md, we find, in red border, the section Constitution of the Republic of Moldova, which allow us to view the same content as the information posted in the compartment Republic of Moldova. The contrast of red and white colors and the name of the important document written entirely in capital letters suggest the webmaster's trend to equip this platform of renovated official web-page of the Presidency with technological elements that facilitate browsing and finding useful information. For the same purpose, in the upper right part of the home page of this website are posted (below the most recent photo of the President) the following compartments with online information: Press Releases, Photo Gallery, Video Gallery. The section Contact (from the left lower part of the main page of this site) includes two address and contact numbers of the Presidential Administration, contact details (including name, contact numbers, e-mail) of the following officials: Chief of Petition and Audiences Section, Chief of Citizenship an Reprieve Service, Chief of State Award Service, State Heraldist, Senior PR Consultant. Thus, the only way to establish a direct dialogue with the president becomes possible only by accessing the Facebook and Twitter pages of Moldovan President.

The specialists in the field have delineated, in order to obtain precise results in the case of quantitative analysis of political websites, the following information indicators: biography of the political leader, data on his political activity, slogan, fragment of the discourse by which is succinctly expressed the political commitment of communicator, press releases, press reviews, news, agenda events, calendar of main activities, e-subscriptions, site search engine, links to other official websites, links to Facebook, Twitter, YouTube, popular social networking sites (Ok.ru, vk.com). The presence of these structural elements of a political website allow having an asymmetric communication characterized by unidirectional flow of information, low level of online interactivity, most frequently known in the case of institutional political websites as one-to-many model of communication. Systematizing the amount of information posted on the official website of the President of Moldova, we identify, on the basis of the criterion topics and frequency of updating messages the following three main categories of information:

1. general information about the Chief of the State, data on the presidency and the country that he represents (not upgraded or discounted rarely, only if this is necessary);

2. information for the press service, downloaded and later released to the public (which includes: photo gallery, audio gallery, speeches and press releases of the main political leader of the country - information updated weekly or more often, depending on the agenda);

3. data concerning the biography and the activity of the First Lady Margarita Timofti (related to social involvement, his participation in events, interviews, photo gallery, video gallery, updated often - according to the calendar of events).

Therefore, the official website used for the institutional political communication by Mr. Nicolae Timofti, the Ex-President of the Republic of Moldova, contains (in the basis of information indicators) the main structural elements that ensure the distribution of a complete political message, well reviewed by the press service and his advisers. The frequent updates of the compartments Photo Gallery and Video Gallery are the unique interactive elements for such communication as a monologue and with low level of receiver control. Despite quality of the images and sound, as well as the use of the best technical parameters for creating a web-site, the online communication platform www.presedinte.md is an official website in the form of booklet. The impossibility of bidirectional communication, at least as responsive dialogue, is augmented by discourses formulated at the third person singular (in the case of messages concerning the activities of the 
President - press releases and interviews) or at the first person singular in section Speeches and Messages (98\% of this information being addressed to the chiefs of other countries), the absence of contact information of the President, active e-mail address or the option for sending a letter addressed to the President. This interactive element, considered a first step in establishing two-way communication between the Chief of the State and citizens, was present in the old version of the official website of Moldovan Presidency (it could be accessed in the sections Republic of Moldova, Useful Links), but for unclear reasons it has not been retrieved (like some rarely updated information) on the new online communication platform.

We find a similar situation in the case of the analysis of the official website of the President of Romania. This online communication platform has only one interactive element that can be accessed from the bottom of the home page - the option Send a message to the President.

Russian citizens have the possibility of direct dialogue with the President due to the following interactive elements:

1. Send a Letter to the President (includes: the rules concerning the conditions for sending an online message at the attention of the Chief of the State, the options Send a letter and Report corruption cases);

2. Reception of citizens (with contact information: number of the phone free of charge for citizens living in Russia, conditions and hours of receipt);

3. Online reception of citizens (allows users to submit an online petition, directly on this website, procedure followed by the delegation in the territory of the specialists in order to identify and solve the problem);

4. The electronic antechamber of the President of Russian Federation (it is an information system that offers the possibility of a direct dialogue with officials from the Antechamber of the President, works through terminals installed in local administration buildings in 192 cities, with a total of approx. 70000 inhabitants, situated at a distance of $100 \mathrm{~km}$. from the city of Moscow);

5. Information (this section contains useful information and telephone numbers that can be used for consultations with Russian President Administration employees, the telephone number where can be sent free SMS).

All these options are part of the page Receiving messages, managed by the team of specialists in the field - employees of the Presidential Directorate for Correspondence with Citizens and Organizations. The option Monitoring messages presents vast statistical information concerning the number of interventions by Russian President or the Presidential Administration in solving various social problems reported on this official website due to the interactive process of political communication. Thus in October 2015, on the official website of the Mr. Vladimir Putin, the President of Russian Federation, was received 88488 complaints, of which 60535 in the electronic document format [10]. Data from this section are the argument of citizens' confidence in the country's political system, of the active involvement of civil society in politics and the functioning of participatory democracy. 
The research team of the University of Rochester (Paul Ferber, Frantz Foltz, Rudy Pugliese) indicated in the list of main interactivity indicators of political websites the following elements:

- $\quad$ active e-mail address of the political actor (or online form) allowing the establishment of oneway communication with high level of receiver control,

- $\quad$ active e-mail address, online form or contact details of the technical staff - an indicator of the unidirectional flow of information and the low level of receiver control,

- $\quad$ e-subscriptions, which allow the two-way communication, with a low receiver control,

- $\quad$ site search engine, considered an element that favors the two-way communication with low level of receiver control,

- virtual tours and interactive educational materials - are 2 other indicators of two-way communication with low level of receiver control. In the case of presidential communication, the virtual tours reinforce the political actor attribution ads official representative of the State who is authorized to promote the country's image, while educational materials contribute to the formation of the political culture of the citizens, understanding the role of civil society for the development of a democratic state, strengthening civic responsibility,

- personal websites, through which it is possible the bidirectional communication between politicians and citizens with high level of receiver control,

- $\quad$ online opinion polls - elements of three-way communication, with low level of receiver control,

- $\quad$ public forums - items of three-way communication, with high level of receiver control [1].

Considering these interactivity indicators of political websites, we note the presence of links to the pages of Facebook, YouTube and Twitter of the Ex-President of the Republic of Moldova and we appreciate the effort of the political leader to speak directly with young people and to provide them with the possibility of free expression by posting comments (likes) or to express interest for the problems of political and economic system of the country. Thus, young people from Moldova, thanks to these interactive forms of new media and their ability to become actors of presidential communication (acting as receivers of the political message forwarded through the new channel the Internet), are an active part of the establishment and development of participatory democracy. They have access to political information and the freedom to express "their agreement or disagreement regarding the political positions of the President" [3, p.333].

\section{Conclusion}

The investigation of official website of Mr. Klaus Iohannis, the President of Romania, as well as the analysis, on the same indicators of interactivity, of the official website of Mr. Vladimir Putin, the President of Russian Federation, allowed us to observe the endowment of these means of online communication with several technical options that favor the creation of public deliberation and democratic dialogue between the Head of State and citizens. Based on these technological features and in order to optimize the presidential communication in Republic of Moldova we propose the following recommendations: 
1. to create and to use the interactive element Send a message to the President,

2. the endowment of official website of the President of the Republic of Moldova with some interactive elements which would favor the development of two-way communication and which will contribute to promoting a positive image of the country and to strengthen citizens' political culture. We are referring in this case to the development, on the example the official website of the President of Russia, of a virtual tour or interactive educational materials,

3. to equip the official website of the President of the Republic of Moldova with interactive communication options, due to which the country's citizens could submit reclamations or complaints of corruption (on the model of the online communication platform http://kremlin.ru),

4. to create a personal website of the President of the Republic of Moldova (on the example of websites http://putin.kremlin.ru/ and http://www.iohannispresedinte.ro/ ).

It will improve the communication between the Head of State and citizens by the element the personalization of political communication.

The practical application of these recommendations will help improve the technical dimension of communication and the effective use of digital arsenal of presidential communication will contribute to revitalize and "to renovate the political life" [2, p. 130].

\section{References}

[1] FERBER, P., FOLTZ, Fr. and PUGLIESE, R.: Cyberdemocracy and Online Politics: A New Model of Interactivity. In: Bulletin of Science, Technology \& Society, No. 5, 2007.

[2] HEINDERYCKS, F. : Obama 2008: l'inflexion numérique. In: Stegner Th. Le Marketig politique. Paris: CNRS Editions, 2012.

[3] MCKAY, A., PALETZ, D.: The Presidency and the Media. In: Handbook of political communication research. Mahwah, New Jersey: Lawrence Erlbaum Associated, 2004.

[4] MOUCHON, J. : La communication présidentielle en quête de modèle. In: Hermes: INISTCNRS, No. 17-18, 1995.

[5] PASTOUREAU, M.: Albastru: istoria unei culori. Chișinău: Cartier, 2006.

[6] SINESCU, C.: Comunicare politică. București: Editura Universitară, 2011.

[7] http://www.presedinte.md/ - official website of the President of the Republic of Moldova

[8] http://www.presidency.ro/ - official website of the President of Romania

[9] http://www.iohannispresedinte.ro/ - personal website of the President of Romania

[10] http://kremlin.ru/ - official website of the President of Russian Federation 
[11] http://putin.kremlin.ru/ - personal website of the President of Russian Federation 